\title{
A design-phase PSA of a nuclear-powered hydrogen plant
}

\author{
Pamela F. Nelson*, Alain Flores, Juan Luis François \\ Laboratorio de Análisis en Ingeniería de Reactores Nucleares, Facultad de Ingeniería-UNAM, \\ Paseo Cucuhnáhuac 8532, Jiutepec, Morelos 62550, Mexico
}

\begin{abstract}
A probabilistic safety assessment (PSA) is being developed for a steam-methane reforming hydrogen production plant linked to a high-temperature gas-cooled nuclear reactor (HTGR). This work is based on the Japan Atomic Energy Research Institute's (JAERI) High Temperature Engineering Test Reactor (HTTR) prototype in Japan. The objective of this paper is to show how the PSA can be used for improving the design of the coupled plants. A simplified HAZOP study was performed to identify initiating events, based on existing studies. The results of the PSA show that the average frequency of an accident at this complex that could affect the population is $7 \times 10^{-8}$ year $^{-1}$ which is divided into the various end states. The dominant sequences are those that result in a methane explosion and occur with a frequency of $6.5 \times 10^{-8}$ year $^{-1}$, while the other sequences are much less frequent. The health risk presents itself if there are people in the vicinity who could be affected by the explosion. This analysis also demonstrates that an accident in one of the plants has little effect on the other. This is true given the design base distance between the plants, the fact that the reactor is underground, as well as other safety characteristics of the HTGR.
\end{abstract}

\section{Introduction}

The increase in world population and consequently in energy demand, the progressive decrease in the fossil fuel reserves, and the environmental pollution associated with the combustion, have attracted the attention of researchers toward the search for new energy alternatives. Hydrogen is one of these and has lots of advantage for the environment. It is a clean fuel when burned with air produces non-contaminating emissions. In addition to direct combustion, work has begun in developing technologies based on fuel cells to transform chemical energy to electric energy and steam. Hydrogen and fuel cells have the potential to solve several major challenges facing the world today: dependence on fossil fuels, poor air quality and greenhouse gas emissions.

Hydrogen can make an effective contribution to the reduction of the greenhouse gas emissions, in particular in the transport and power generation sectors. In fact, developed countries have a high dependency on gasoline use in transportation, and developing countries are heading in the same direction. Changing gasoline and diesel-based transportation into hydrogen fuel will

\footnotetext{
* Corresponding author. Tel.: +52 7773193282; fax: +527773194101

E-mail address: pnelson@lairn.fi-p.unam.mx (P.F. Nelson).
}

result in a tremendous improvement in the energy conversion efficiency. Vehicles burning gasoline and diesel are noticeably inefficient: North American cars are about $15 \%$ efficient, new European cars are close to $25 \%$ efficient, meanwhile fuel cells burning hydrogen, although still in their first stage of development, already achieve over 50\% efficiency (Miller and Duffey, 2005).

Hydrogen is not a primary energy source like coal and gas; it is an energy carrier. Initially, it will be produced using existing energy systems based on different conventional primary energy carriers and sources. Hydrogen produced from fossil-based energy conversion systems with capture, and safe storage (sequestration) of $\mathrm{CO}_{2}$ emissions, is almost a completely carbon-free energy pathway. In the longer term, renewable (solar, wind, biomass, etc.) and nuclear energy sources will become the most important source for the production of hydrogen.

Presently the two main processes to produce hydrogen are: steam-methane reforming and electrolysis. The former is now dominantly used world wide to produce hydrogen, mainly due to its economic advantage over electrolysis. Most hydrogen production today is produced by steam-methane reformers typically in world-scale plants producing 200-300 tonnes/day. This scale of plant produces enough hydrogen to fuel around half a million light vehicles (Miller, 2004). Other advanced technologies, 
like high temperature electrolysis and thermochemical cycles are under development worldwide.

Hydrogen produced from nuclear energy conversion systems is under investigation around the world, most of them based on steam-methane reforming, electrolysis, thermochemical cycles and high temperature electrolysis. In particular the Japan Atomic Energy Research Institute (JAERI) is developing a prototype plant to demonstrate the feasibility of hydrogen production under the steam-methane reforming process coupled to a high-temperature gas-cooled reactor: the High Temperature Engineering Test Reactor (HTTR).

Therefore, the safety of the three components of the complex should be analyzed: the hydrogen plant, the nuclear reactor and the coupling of the two. When handled properly, hydrogen is a very safe fuel. However, like all fuels, hydrogen has energy and must be treated with respect. The recent high-temperature gas-cooled reactors are promising to be very safe; however, the use of probabilistic safety assessment (PSA) and risk-informed design can increase safety even further. One of the most important limitations of the study is the lack of operational experience; however, generic data is employed for these analyses and the results are useful in the design phase. The HTTR in Japan was used as a basis for the study since the necessary information of the plant was available. Although the HTTR is in operation, the chemical plant will be not put into operation until 2008. For this reason the generic data were used and will be described throughout the paper. Since ranking is a useful output from PSA, we will observe that the actual values are not as important as the relative ranking of the importance of the components to safety. To do this, initiating events were postulated by development of a HAZOP study based on the JAERI installation in Japan. The approach of this study was to identify and quantify health risks in order to find key points for improvement.

The required information was gathered from publicly available documents in order to describe the systems and components of the HTTR (JAERI, 2005). The P\&IDs of the plant were developed based on the information available (Inagaki et al., 2003). Generic failure rates were used in the analysis. The chemical plant component failure rates were taken from Guidelines for Process Equipment Reliability Data with Data Tables (AICHE, 1989), and the nuclear component failure rates from the PRA Procedure's Guide (Bari et al., 1985) and a study on operational experience at a high-temperature gas-cooled nuclear reactor (HTGR), Fort St. Vrain (Copinger and Moses, 2004).

Initiating events were postulated based on a HAZOP type study on the JAERI installation in Japan. Because the idea was to identify and quantify health risks in order to find key points for improvement, event trees were constructed for three initiating events that could most impact public health (see items 3,8 and 11 in Table 1). Since the objective of this paper is to show how the PSA can be used for improving the design of the coupled plants, it is necessary to present possible accident sequences, the end states or consequences and their frequencies. It was possible to define different end states; not all result in explosion or some kind of effect on health, as some are purely economic damage to the plant. With this information it was possible to determine the components that contribute most to the accidents and perform various sensitivity studies in order to determine how to reduce the frequency of the events.

\section{Description of the complex}

It is necessary to fully understand the design of the plants that constitute the complex and their safety systems in order to be able to develop the event trees and reflect in them the chronology of the actuation of the mitigating systems. Complete knowledge about the components of the safety systems is also crucial to the development of the fault trees and data base. Given the limited information available, assumptions were made when necessary and are indicated as such throughout the paper. A brief description is provided of the HTTR and the hydrogen production, which uses the methane reforming process.

\subsection{Main HTTR safety systems}

One of the main characteristics of HTTR safety is the fuel design, which consists of coated fuel particles (CFP's) that should not fail during normal operation and anticipated operational occurrences (AOO's). Among the safety characteristics of the reactor are the following: the maximum fuel temperature does not exceed $1600^{\circ} \mathrm{C}$ in any $\mathrm{AOO}$. The reactor will be shut down in a safe and reliable way during operation using a control rod system. In addition, the reserve shutdown system (RSS) is independent of the control rod system. Another system is designed to remove decay heat after reactor shutdown for any AOO or accident. The HTTR has a containment vessel to prevent a release of fission products (FP's) and an excessive ingress of air in the case of a depressurization accident. The pressure in the pressurized water cooling system (PWCS) will be controlled and will have less pressure than that of the primary helium to prevent a large ingress of water into the core in case of a heat exchanger tube rupture in the pressurized primary water cooler (PPWC). The pressure of the helium in the secondary helium cooling system (SHCS) will be slightly higher than the primary to prevent release of fission products, from the primary cooling system (PCS) to the secondary, through a break in the heat exchanger (IHX) pipe. A full description of the HTTR can be found in the JAERI website (JAERI, 2005).

In order to couple the plants, the secondary pressurized water cooler is removed and the high temperature helium is sent to the chemical plant. Two isolation valves are added outside the containment in order to be able to isolate the plants when necessary.

\subsection{Description of the chemical plant}

\subsubsection{Description of the methane reforming process}

One of the most efficient and economic ways to generate hydrogen is by the methane reforming process, although the use of this method generates carbon dioxide, the production of this greenhouse gas is reduced by almost $22 \%$ when using a nuclear reactor as the heat source (Flores et al., 2004). The methane reforming method consists of breaking the link between the carbon and the hydrogen in the methane, with the help of heat and 
Table 1

HAZOP action report

\begin{tabular}{|c|c|c|c|c|}
\hline & Guide word & Possible cause & Consequences & Suggested action \\
\hline 1 & Less flow & $\begin{array}{l}\text { Process gas leak } \\
\text { (hydrogen) }\end{array}$ & $\begin{array}{l}\text { Accumulation of explosive mixture (in an } \\
\text { enclosed place) }\end{array}$ & $\begin{array}{l}\text { Detector. Relief valves in the } \\
\text { containment }\end{array}$ \\
\hline 2 & Less flow & $\begin{array}{l}\text { Helium line break in the } \\
\text { reformer }\end{array}$ & $\begin{array}{l}\text { Loss of coolant, over heating of the heat } \\
\text { exchanger }\end{array}$ & $\begin{array}{l}\text { Sensors to detect a leak. Helium } \\
\text { cutoff to the feed gas circuit }\end{array}$ \\
\hline 3 & Less flow & Helium return line leak & $\begin{array}{l}\text { Temperature increase in the heat exchanger, } \\
\text { temperature increase in the primary Helium } \\
\text { circuit }\end{array}$ & $\begin{array}{l}\text { Flow detectors, reactor shutdown, } \\
\text { isolation valve closure, feedgas } \\
\text { and water closure, activation of } \\
\text { auxiliary cooling system, vents }\end{array}$ \\
\hline 4 & Less flow & Loss of feedwater & $\begin{array}{l}\text { Thermal rupture of the methane, carbon } \\
\text { accumulation in the reformer tubes }\end{array}$ & Feedwater backup system \\
\hline 5 & Less pressure & $\begin{array}{l}\text { Loss of pressure accident: } \\
\text { nitrogen pipe break }\end{array}$ & $\begin{array}{l}\text { If normal shutdown is required, the nitrogen } \\
\text { could not be used to purge the line and the } \\
\text { methane would have to be vented, possible } \\
\text { damage to catalyst due to steam } \\
\text { condensation. The plant cannot start up } \\
\text { without this line }\end{array}$ & $\begin{array}{l}\text { Leak detectors and pressure } \\
\text { controllers, vents to chimney }\end{array}$ \\
\hline 6 & Less flow & $\begin{array}{l}\text { Methane line break } \\
\text { (methane) }\end{array}$ & $\begin{array}{l}\text { Accumulation of flammable mixture and } \\
\text { possible explosion }\end{array}$ & $\begin{array}{l}\text { Appropriate detection devices, } \\
\text { sufficient distance between } \\
\text { plants, wall to absorb explosion, } \\
\text { isolation valves }\end{array}$ \\
\hline 7 & Corrosion & Reformer tube leak & Contamination & Material research \\
\hline 8 & Less pressure & Helium duct rupture & $\begin{array}{l}\text { Loss of coolant, FP release, oxidation of } \\
\text { internal graphite structures in the core }\end{array}$ & $\begin{array}{l}\text { Fission product release barriers, } \\
\text { air purification system, isolation } \\
\text { of the containment }\end{array}$ \\
\hline 9 & Less flow & VCS water line break & $\begin{array}{l}\text { Heating of the concrete wall around the } \\
\text { reactor vessel }\end{array}$ & Level, flow and pressure detectors \\
\hline 10 & Less flow & $\begin{array}{l}\text { ACS pressurized water } \\
\text { line }\end{array}$ & $\begin{array}{l}\text { This system does not function during } \\
\text { operation, in case of an emergency shutdown } \\
\text { ACS can be used, if the break is in the AHX, } \\
\text { the water could enter the reactor core }\end{array}$ & $\begin{array}{l}\text { Flow and pressure detectors, } \\
\text { backup system to ACS }\end{array}$ \\
\hline 11 & Less flow & PPWC tube break & $\begin{array}{l}\text { Loss of coolant to PPWC, temperature } \\
\text { increase. If the break is inside the PPWC, } \\
\text { water can ingress to the core, increase in } \\
\text { reactivity, oxidation of internal graphite } \\
\text { structures, fission product release, possible } \\
\text { production of hydrogen inside the reactor } \\
\text { and explosion }\end{array}$ & $\begin{array}{l}\text { Isolation valves for feedwater to } \\
\text { PWCS, pressure detectors }\end{array}$ \\
\hline
\end{tabular}

steam, this causes the carbon to oxidize generating carbon dioxide and hydrogen.

The methane reforming process is the following: natural gas is injected and passes through a desulfurizer to reduce the production of $\mathrm{SO}_{x}$, once the level of sulfur in the natural gas is reduced, it is mixed with superheated steam and enters the reformer where carbon monoxide and hydrogen are produced.
More water is added to the resulting mixture to generate more hydrogen and generate carbon dioxide, which is less contaminating than carbon monoxide; this reaction takes place in a shift reactor. A modular representation of the process is shown in Fig. 1.

A diagram was constructed on the basis of available information about the coupling of the HTTR and the steam methane

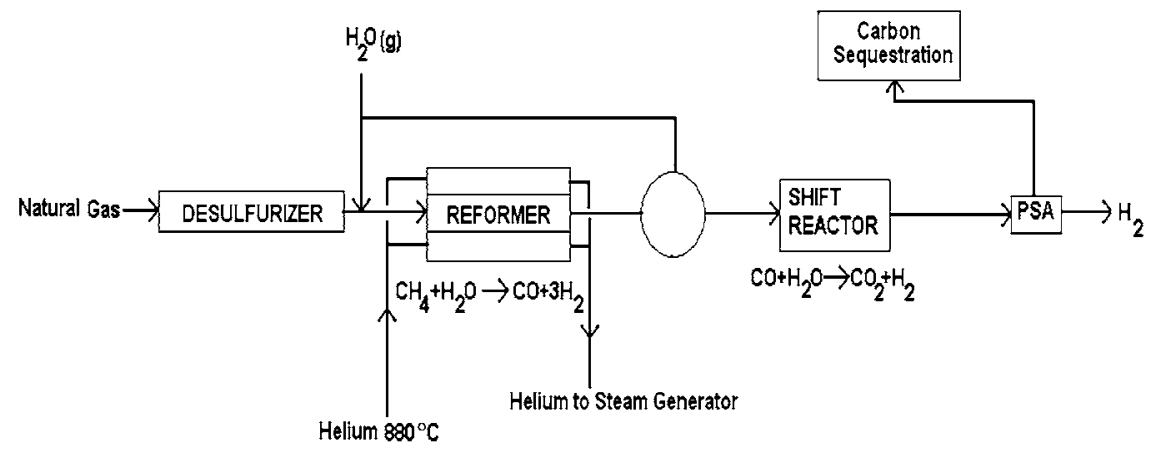

Fig. 1. Methane reforming process. 


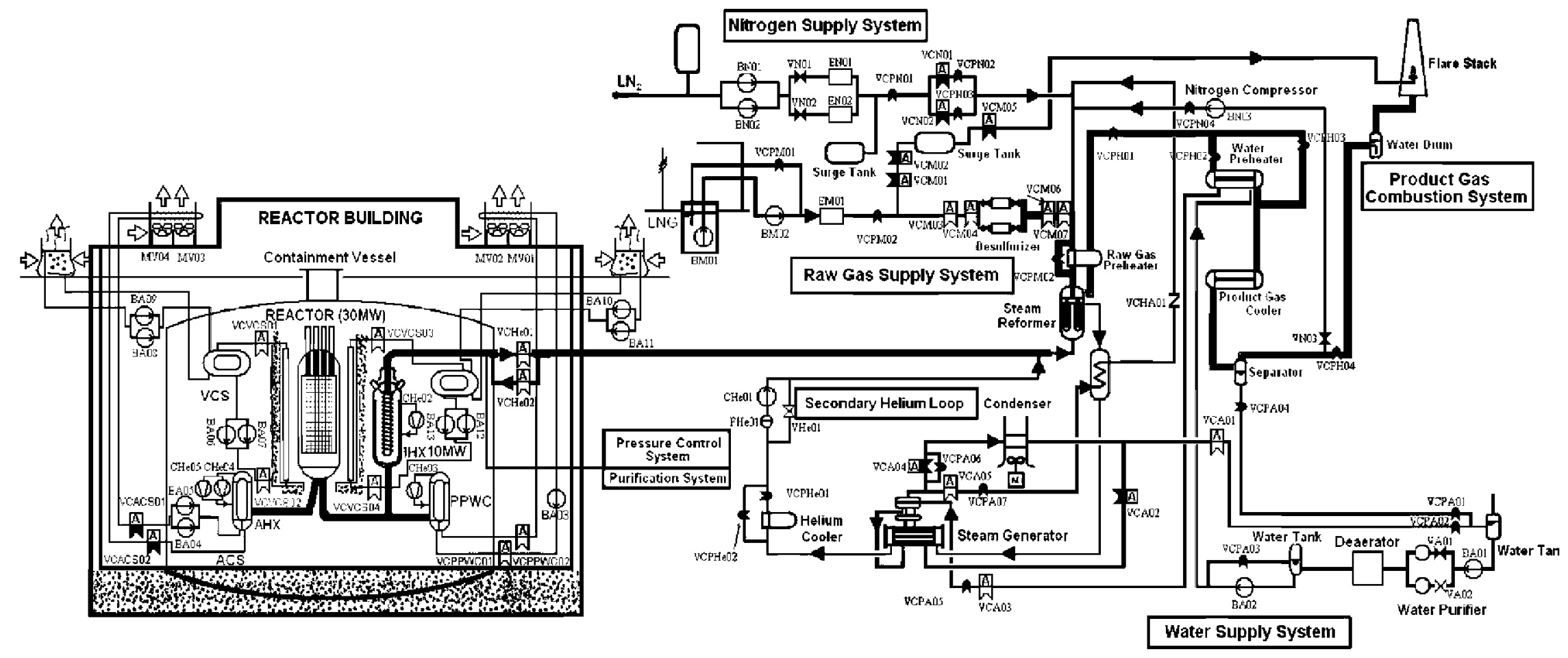

Fig. 2. Coupling of HTTR and methane reforming plant. 
reforming plant and is presented in Fig. 2. The development of the initiating events and the accident sequences is based on this diagram.

\section{Initiating events and accident sequences}

In order to identify initiating events, a table was developed to describe the possible consequences due to deviations in the normal operation of the plants, as is done in the HAZOP technique. The information was taken from studies on the HTTR as well as events that have occurred in HTGRs (basically Fort St. Vrain) and hydrogen plants. Due to the fact that many of the operational deviations lead to purely economic damage, these initiators were not included in the event tree analysis presented here. Further work is being performed on other initiators in order to include them in the design improvement process proposed here.

\subsection{HAZOP}

The diagram in Fig. 2 was divided into systems, and different guide words were applied to discover the possible consequences of that particular deviation from normal operation. The helium lines were separated into three subsystems: that which leaves the reactor towards the main cooling system (MCS), that which goes to the auxiliary cooling system (ACS) and the secondary helium loop that exits the heat exchanger and heads to the chemical plant. Table 1 shows the compilation of information presented in the HAZOP action report format.

After analyzing each system line with the aid of this HAZOP format, the events were chosen based on their effect on public health, resulting in three events: methane line break, the helium duct rupture and PPWC heat exchanger tube break, which correspond to the events 6,8 and 11 in Table 1 . The initiating event (number 6 in the table) corresponds to a methane pipe break and could result in consequences such as explosion and fire, the initiating event 8 corresponds to a rupture in the primary helium duct that could result in loss of coolant in the reactor and fission product release and finally, the event 11 is due to a PPWC heat exchanger tube break which could result in an ingress of water to the reactor core that could produce hydrogen in the core and lead to a hydrogen explosion. Each of these failures was postulated in the location that would cause the most damage. The event trees for each of these initiators are presented below.

\subsection{Accident sequences}

Event trees are used to model the possible accident sequences given a specific initiating event. Since the three initiating events are very different it was necessary to build three different event trees to model them. To do this, the items in the suggested action column can be incorporated as mitigating systems, as well as the existing mitigating systems. Also, mitigating systems from each of the plants must be involved when possible, in order to observe the effect of the deviation from normal operation on the other plant.

\subsubsection{Methane pipe break (RU-ME)}

A value of $2.35 \times 10^{-4}$ year $^{-1}$ (AICHE, 1989) was used for the initiating event frequency; this event was chosen due to the fact that methane is potentially explosive and could cause substantial damage to onsite personnel as well as to the general public.

The event considered is a total break in the methane piping in the place that would cause the most damage and with the least possibility of preventing the explosion. There is a nominal flow of $1400 \mathrm{~kg} / \mathrm{h}$ that leaks from the pipe; it is assumed that the only way to stop the flow in this location is by stopping the pump BM01 (see Fig. 3)

\subsubsection{Location and description of the break}

This event considers a break in the methane pipe as shown in Fig. 3; the break is located between the evaporator EM01 and the pressure control valve VCPM02. When a pressure difference is detected, a signal is sent to stop the pump BM01, while all the

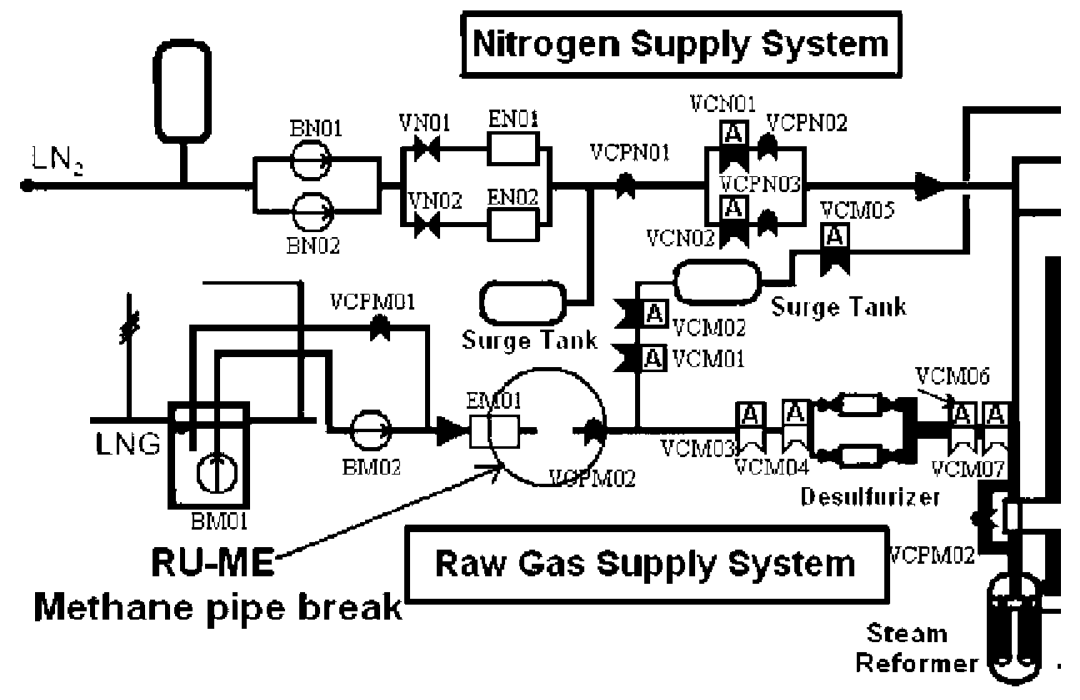

Fig. 3. Location of methane pipe break. 
Table 2

End states for initiating event RU-ME

\begin{tabular}{ll}
\hline End state & Description \\
\hline EXPLOSIONM & Methane explosion \\
DTP & Possible structural damage \\
DTQ & Thermal damage to the chemical plant
\end{tabular}

a The quantity of gas accumulated will depend on the time to repair the pump BM01; calculations revealed that more than $200 \mathrm{~kg}$ of methane would accumulate in $10 \mathrm{~min}$, and if it were to ignite it could cause second degree burns after $20 \mathrm{~s}$ of exposition to people located $100 \mathrm{~m}$ from the center of the fire (Flores, 2005).

helium from the reactor is sent to the PPWC. If for some reason the flow cannot be diverted or a SCRAM must be initiated, the PPWC is designed to dissipate the $30 \mathrm{MW}$ from the reactor.

If there is a SCRAM in an accident condition, the MCS, which consists of the PPWC and IHX, stops and the ACS starts in order to remove the decay heat from the reactor, the operating vessel cooling system (VCS) also helps ro remove heat. In these event trees we consider the possibility of the VCS to fail to continue operating; however, even if the VCS stops during the accident condition, a concrete biological shield around the VCS can absorb the heat from the core. The VCS failure will not cause the core to melt like the ECCS failure in a light water reactor. Despite this, the end state DTP is included to determine whether further study is necessary on any kind of structural damage that could be caused when the active cooling sytems fail. The VCS failure is not considered when there is a failure to shutdown, due to the very small resulting probability.

\subsubsection{Results for the initiating event $R U-M E$}

Fig. 4 presents the event tree that was built for this initiating event using the computer program, SAPHIRE, developed by the Idaho National Laboratory (Russell and Hoffman, 1998).

Table 2 presents the definition of the possible end states for the event tree presented in Fig. 4. Although the last two of the end states do not cause health effects, they are considered because of the economic effect that they imply due to plant damage.

Fault trees were constructed to be able to calculate the frequencies of the sequences, one for each mitigating system shown in the headings of the event trees. The level of detail in the fault
Table 3

System failure probabilities for RU-ME

\begin{tabular}{ll}
\hline System & Failure probability \\
\hline VCS & $9.84 \times 10^{-3}$ \\
ACS & $6.59 \times 10^{-3}$ \\
DESV & $2.54 \times 10^{-4}$ \\
META & $2.53 \times 10^{-4}$ \\
APAG & $5.10 \times 10^{-6}$ \\
\hline
\end{tabular}

trees reached the component level, and their power supply was considered as a support system; other support systems were not considered due to the lack of detailed enough information. The failure of the power supply as an initiating event has been analyzed and was not found to be a dominant contributor to the consequences.

The fault trees are not presented in this paper, they can be found in the full report (Flores, 2005). The fault trees were built and quantified with SAPHIRE also. The failure rates for each component were obtained from various references, including the PRA Procedures Guide (Bari et al., 1985) and the Guide for reliability data in the process industry (AICHE, 1989). Data for the failure of the operator to shut down the reactor and the failure of the insertion of the control rods were taken from the report on the operational experience in Fort St. Vrain, a high-temperature gas-cooled reactor that operated in the United States for 10 years (Copinger and Moses, 2004).

The fault trees are used to calculate the probability of failure of each system; Table 3 shows the results of the failure probability for each system involved in the event tree for the initiating event RU-ME.

Once the fault trees were evaluated, the frequencies of the accident sequences were quantified. The sequences were grouped by end states in order to evaluate the frequencies of the possible consequences for this event. The results for all the end states considered in this paper are shown in Section 4. In particular, the results for this event tree show a mean frequency of $6.53 \times 10^{-8}$ year $^{-1}$ for a methane explosion, $2.60 \times 10^{-7}$ year $^{-1}$ for DTP, and $3.15 \times 10^{-13}$ year $^{-1}$ for DTQ, the last two end states represent only economic loss due to some type of structural damage.

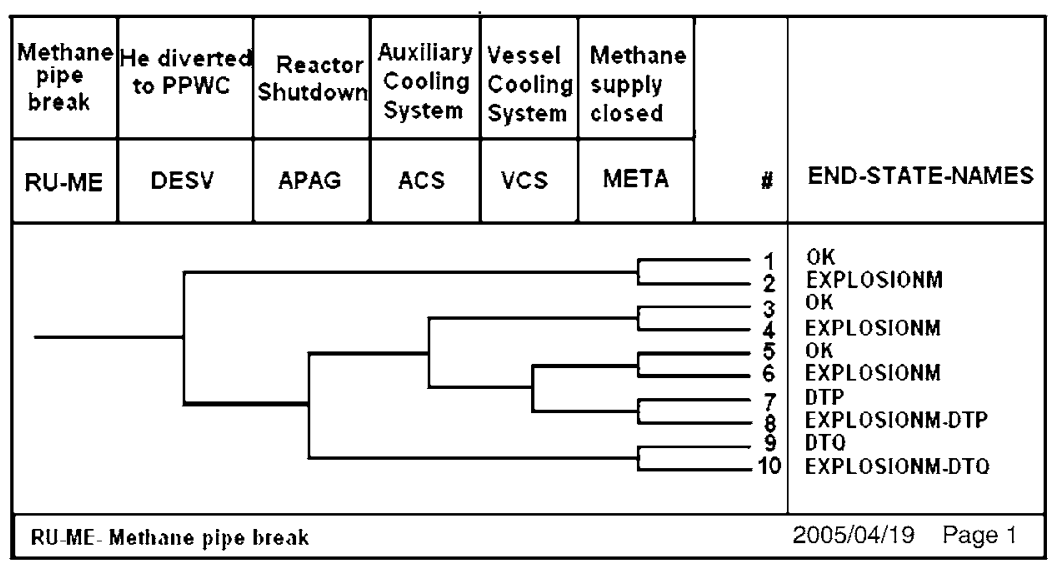

Fig. 4. Event tree for the initiating event RU-ME. 


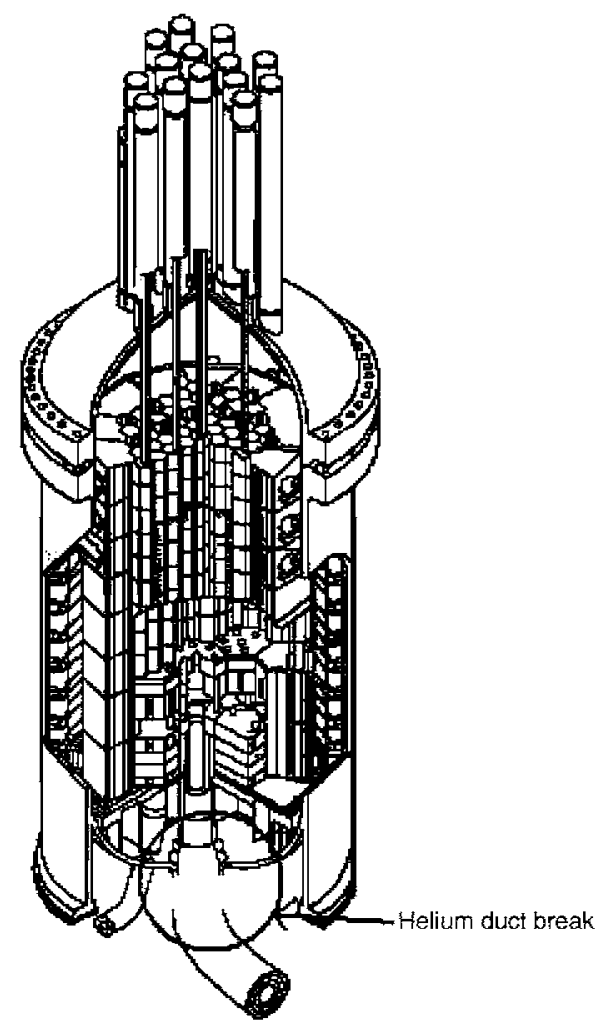

Fig. 5. Location of the helium pipe break RU-HE.

\subsection{Helium duct rupture (RU-HE)}

This event is considered the worst event by the HTTR designers, and is referred to as a depressurization accident. It consists of a total rupture of the coaxial pipe that goes to the PPWC and the heat exchanger (IHX). This break could cause the coolant to flow out of the pressurized vessel and leave the reactor without coolant, in such a way that the ACS would not be available and the only way to remove the residual heat is with the VCS.

\subsubsection{Description of the helium duct break}

A frequency of $2.12 \times 10^{-5}$ year $^{-1}$ is considered for this large break (Russell and Hoffman, 1998) and it is localized in the inlet nozzle of the pressurized vessel, as illustrated in Fig. 5. When the pressure difference is detected, a SCRAM occurs and
Table 4

End states for helium duct break

DTP Possible structural damage
FP
DT
$\begin{aligned} & \text { Structural damage } \\ & { }^{a} \text { The sources of FP considered in the analysis are: FP in the primary coolant, }\end{aligned}$
FP that plate out on the primary coolant system and FP contained in the core
which could be liberated during an accident.
b The HTTR is designed to have a negative feedback due to the Doppler effect
of the fuel, thus there is no fuel damage since $1600^{\circ} \mathrm{C}$ will not be surpassed.

Table 5

System failure probabilities

\begin{tabular}{ll}
\hline System & Failure probability \\
\hline VCS & $9.84 \times 10^{-3}$ \\
AGUA-PPWC & $4.47 \times 10^{-3}$ \\
CV-VALV & $2.75 \times 10^{-4}$ \\
APAG & $5.10 \times 10^{-6}$ \\
\hline
\end{tabular}

the coolant may be released to the containment. The containment isolation valves must close to avoid release of fission products, although a small quantity may leak to the atmosphere through the service area due to the increase in the containment pressure. The ACS cannot operate under these conditions to prevent the entrance of air into the core. The decay heat is removed by the VCS. When the pressure inside the core and the mixture of helium/air is the same, air may enter by natural convection and oxidize the graphite structures until the VCS cools the reactor and the oxidation reaction stops. Again, failure of the VCS to continue operating is not considered when there is a failure to scram due to the low resulting probability.

\subsubsection{Results for helium duct break $R U-H E$}

By failing the mitigating systems that could enter to avoid possible accident consequences, it was possible to create the event tree presented in Fig. 6. The system entitled CV-VALV, the containment isolation valves, avoids the liberation of fission products out of the vessel containment. The end states for this initiating event are shown in Table 4.

The failure probabilities for the systems are shown in Table 5 .

The system CV-VALV is responsible for the closure of the containment isolation valve to avoid fission product

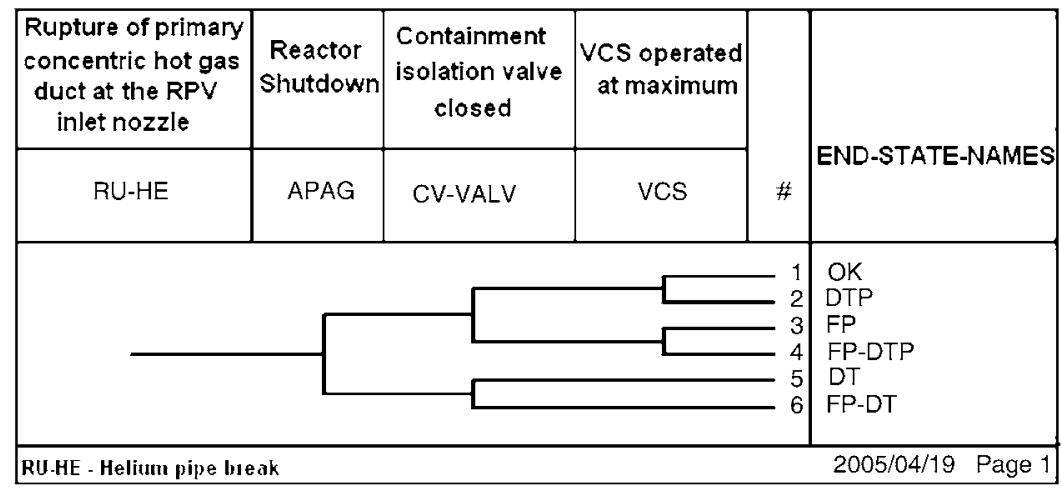

Fig. 6. Event tree for the initiating event RU-HE. 


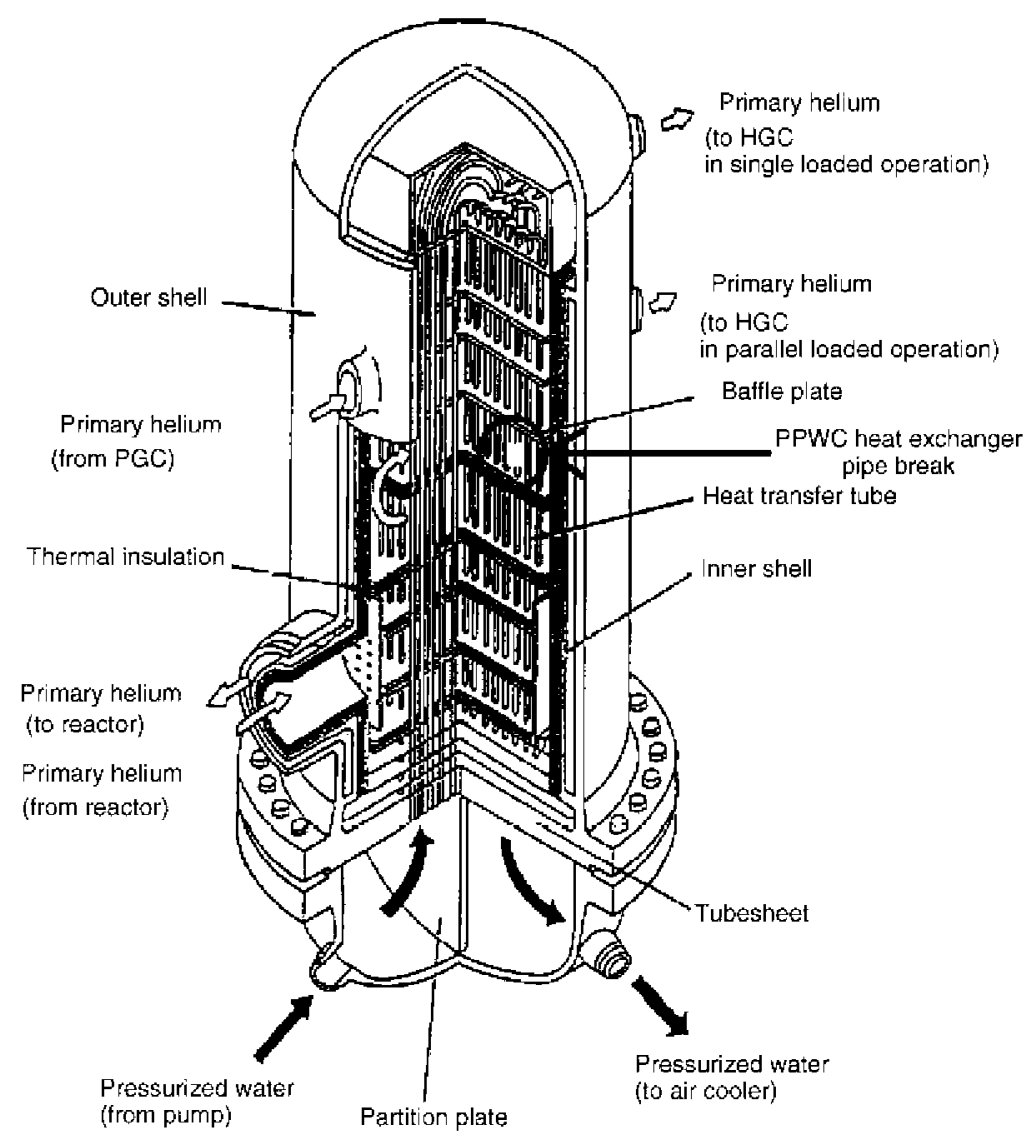

Fig. 7. Location of the break RU-PPWC.

release. Due to the low frequency of this initiating event, $2.12 \times 10^{-5}$ year $^{-1}{ }^{1} \mathrm{FP}$ is a low frequency end state, as can be seen in Section 4. In this case the systems in the chemical plant are not included in the event tree, because it is assumed that the isolation valves between the two plants close. This assumption will be changed in future work by including the possibility of these valves failing.

\subsection{Rupture of a pipe in the PPWC (RU-PPWC)}

This initiating event is assumed to have a frequency of $5 \times 10^{-4}$ year $^{-1}$ (Bari et al., 1985) and is considered important because if a large amount of water were to enter into the reactor, first there is a probability that the internal graphite structures could be oxidized and if the reactor is not shut down, hydrogen would be produced in the core, possibly resulting in an explosion.

\subsubsection{Location and description of the event $R U-P P W C$}

In the case of a break in a heat exchanger pipe inside the PPWC (see Fig. 7), the pressurized water could enter into the primary helium loop and if so would evaporate given the heat of the structures in the reactor. The water that enters inside the core could cause oxidation of the graphite, as well as increase

\footnotetext{
${ }^{1}$ A large LOCA was assumed, given no data was found for this type concentric
} pipe break.
Table 6

End states for RU-PPWC

\begin{tabular}{ll}
\hline DTP & $\begin{array}{l}\text { Partial structural damage } \\
\text { This refers to the oxidation of the graphite given the } \\
\text { ingress of water into the reactor } \\
\text { Eydrogen explosion in the vessel, given the } \\
\text { accumulation of hydrogen in the core }\end{array}$ \\
EXPLOSIONH2-FP & $\begin{array}{l}\text { Similar to the above, but the containment is not } \\
\text { isolated in this case and fission products are released } \\
\text { to the environment }\end{array}$
\end{tabular}

the reactivity. A SCRAM occurs when a decrease is detected in the pressure between the primary helium gas and the pressurized water. Simultaneously, the PPWC is isolated from the water pump by closing an isolation valve to prevent an even greater ingress of water into the reactor core. Again, the systems in the chemical plant are assumed to be unaffected by the event.

\subsubsection{Results for the event RU-PPWC}

The event tree was developed for the PPWC heat exchanger pipe break and is presented in Fig. 8, and the end states are shown in Table 6.

\section{General results}

Table 7 shows the failure probability of each system and Table 8 shows the frequency of each end state in descending 


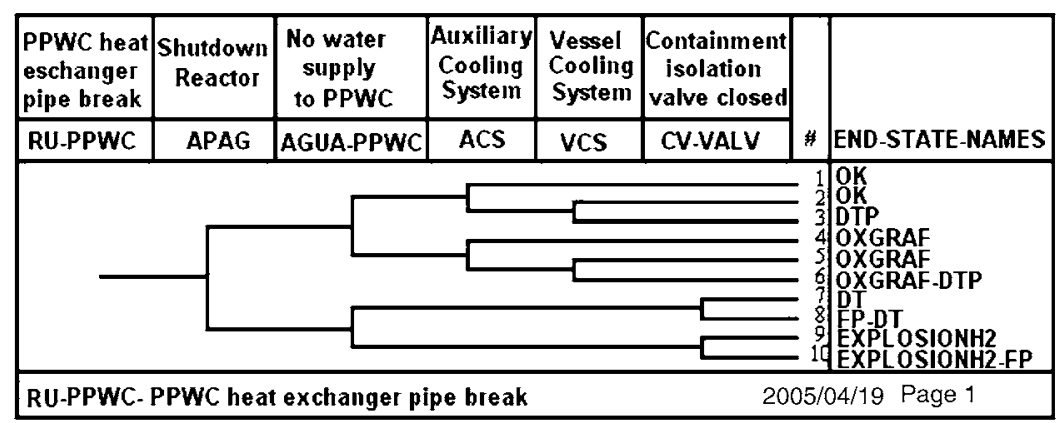

Fig. 8. Event tree for the initiating event RU-PPWC.

Table 7

Probability of system failure

Fault Trea Review - (HTTR-H2)
\begin{tabular}{|l|c|c|c|c|c|}
\hline Fault Tree & Frequency & Mean & 5 th & Median & 95 th \\
\hline VCS & $1.015 \mathrm{E}-02$ & $9.843 \mathrm{E}-0.3$ & $4.579 \mathrm{E}-03$ & $8.872 \mathrm{E}-03$ & $1.847 \mathrm{E}-02$ \\
\hline ACS & $8.452 \mathrm{E}-03$ & $6.587 \mathrm{E}-03$ & $1.974 \mathrm{E}-03$ & $4.982 \mathrm{E}-03$ & $1.523 \mathrm{E}-02$ \\
\hline AGUA-PPAC & $4.672 \mathrm{E}-03$ & $4.470 \mathrm{E}-03$ & $1.285 \mathrm{E}-03$ & $3.352 \mathrm{E}-03$ & $1.155 \mathrm{E}-02$ \\
\hline CV-YALY & $2.828 \mathrm{E}-04$ & $2.752 \mathrm{E}-04$ & $1.781 \mathrm{E}-05$ & $1.466 \mathrm{E}-04$ & $8.813 \mathrm{E}-04$ \\
\hline DESV & $2.780 \mathrm{E}-04$ & $2.538 \mathrm{E}-04$ & $1.345 \mathrm{E}-05$ & $1.183 \mathrm{E}-04$ & $9.473 \mathrm{E}-04$ \\
\hline META & $2.780 \mathrm{E}-04$ & $2.538 \mathrm{E}-04$ & $1.345 \mathrm{E}-05$ & $1.183 \mathrm{E}-04$ & $9.473 \mathrm{E}-04$ \\
\hline APAG & $4.816 \mathrm{E}-06$ & $5.096 \mathrm{E}-0.05$ & $4.158 \mathrm{E}-07$ & $2.335 \mathrm{E}-06$ & $1.951 \mathrm{E}-05$ \\
\hline
\end{tabular}

order, including the end states that represent economic loss only (OXGRAF, DTP, DT and DTQ) with the largest probabilities. The point value, mean, 5 and $95 \%$ values are shown here as calculated in the uncertainty analysis.

From Table 7 we can observe that the system with the greatest failure probability is the VCS. Although the VCS has the largest failure probability, it is not the system that contributes most to

Table 8

All end state frequencies

\begin{tabular}{|c|c|c|c|c|c|}
\hline \multicolumn{6}{|c|}{ EndState Review - (HTR -H2) } \\
\hline End state & Frequency & Mean & 5th & Median & 95th \\
\hline OXGRAF & $2336 \mathrm{E}-\mathrm{IIG}$ & $2215 E-186$ & 5.559E-107 & $1.773 \mathrm{E}-96$ & $5.208 \mathrm{E}-06$ \\
\hline DTP & $2.590 \mathrm{E}-1 \mathrm{~T}$ & $2.458 E-177$ & $4.112 \mathrm{E}-107$ & $2.155 \mathrm{E}-07$ & $4.821 \mathrm{E}-07$ \\
\hline EXPLOSIONM & 6.533E- -118 & $6.5800-198$ & $3.473 E-109$ & $2.76 Z \mathrm{E}-0 \mathrm{O}$ & $2,300 \mathrm{E}-07$ \\
\hline$\overline{\mathrm{FP}}$ & $5996 \mathrm{E}-1 \mathrm{~g}$ & $5.571 \mathrm{E}-99$ & $3878 E-10$ & $2.788 \mathrm{E}-09$ & $2.039 \mathrm{E}-08$ \\
\hline DT & $2.510 \mathrm{E}-09$ & $2.410 \mathrm{DES}$ & $2.3 \% \mathrm{OE}-10$ & $1.171 \mathrm{E}-\mathrm{DQA}$ & $8.295 \mathrm{E}-09$ \\
\hline OXGRAF-DTP & $2.082 \mathrm{E}-10$ & $1.782 \mathrm{E}-10$ & $2.127 \mathrm{E}-11$ & 5.977E-11 & $5325 \mathrm{E}-10$ \\
\hline FP.DTF & $8.108 \mathrm{E}-11$ & $5.775 E-11$ & $3.27 \mathrm{~F}-12$ & $2.4 E \mathrm{EE}-11$ & $1.929 \mathrm{E}-10$ \\
\hline EXPLOS10N/H2 & $1.127 \mathrm{TE}-11$ & $1,120 \mathrm{E}-11$ & $4,349 \mathrm{E}-13$ & $4,15 \mathrm{EE}-12$ & $4.558 \mathrm{E}-11$ \\
\hline FP-OT & $7.100 \mathrm{E}-13$ & $8.922 E-13$ & $1.237 \mathrm{E}-14$ & $1.707 \mathrm{E}-10$ & $2.916 \mathrm{E}-12$ \\
\hline$\overline{D T Q}$ & $3147 \mathrm{E}-13$ & $3.248 E-13$ & $4.790 \mathrm{E}-15$ & $7,313 E-14$ & $1.292 \mathrm{E}-12$ \\
\hline EXPLOSICNH2-FF & $3.186 \mathrm{E}-15$ & $3.129 E-15$ & $2.748 \mathrm{E}-17$ & $5.445 E-16$ & $1.423 \mathrm{E}-14$ \\
\hline EXPLOSIONM-DTF & $1.817 \mathrm{E}-15$ & $1.706 E-15$ & $7.48: 2 \mathrm{E}-18$ & 1.790E-1E & $5.345 \mathrm{E}-15$ \\
\hline EXPLOSIOHM-DTQ & 8749E-17 & $8782 E-17$ & $2.348 E-19$ & $8.114 \mathrm{E}-15$ & $2.59 \mathrm{gE}-16$ \\
\hline TOTALS $=$ & $2.870 \mathrm{E}-016$ & $2.536 \mathrm{E}-16$ & & & \\
\hline
\end{tabular}

the end state frequency. The system that contributes most to an accident that affects health is the methane system (META). The failure or success of the VCS affects the economical aspects more than the health risk.

In Table 8 we can observe that the end state with the highest frequency is the oxidation of the graphite (OXGRAF), which refers to the oxidation of the internal graphite structures in the reactor pressure vessel, again, a purely economic risk end state.

Observing Table 9 we find three end states that provoke damage to the onsite, and possibly offsite, population: EXPLOSIONM, EXPLOSIONH2, FP and these same ocurrences but with different extensions added, such as DT, DTP, and DTQ.

Table 9 shows only the end states that could have an effect on the population in terms of death and injury. The mean frequency is $6.991 \times 10^{-8}$ year $^{-1}$.

\section{Design improvement methodology: importance and sensitivity studies}

There are various importance measures used in PSA, for this study we use the risk reduction importance, that is, the amount of reduction in the frequency of the end states when the basic event being considered is reduced to a probability of 0 . For example, the frequency of the end state EXPLOSIONM is about $6.5 \times 10^{-8}$ year $^{-1}$; if it were necessary to reduce this frequency, it is useful to rank the importance of the components that are involved in these sequences. It was found that the methane 
Table 9

Frequency of end states that affect health

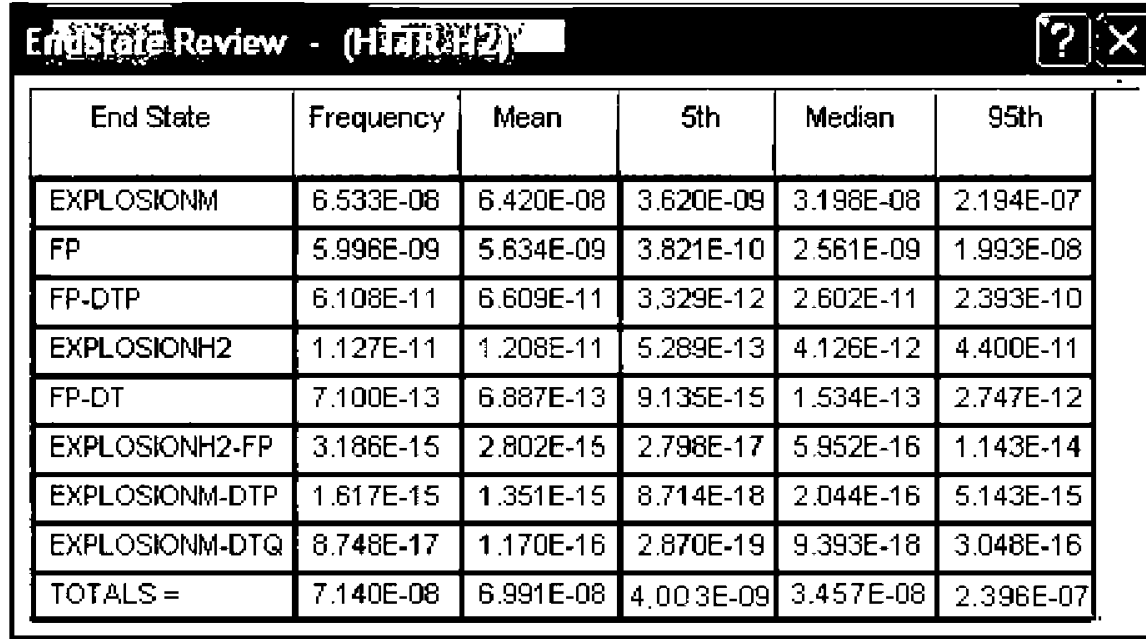

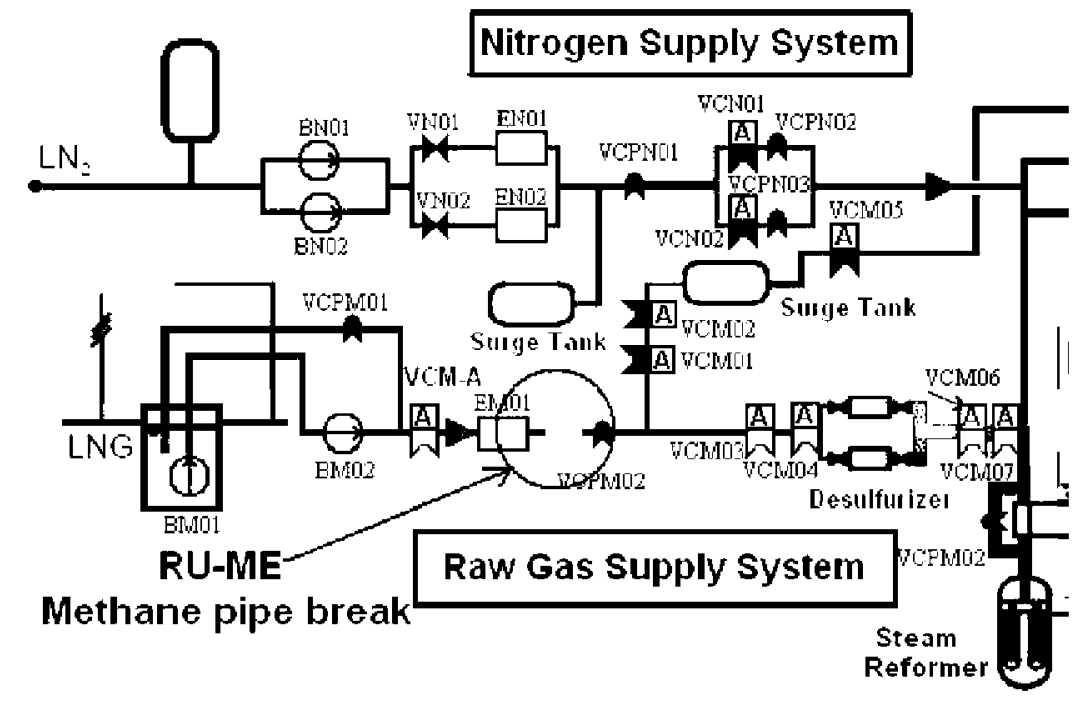

Fig. 9. Cutoff valve VCM-A added to the design.

pump BM01 contributes most to this frequency, since the failure to stop this pump results in an accumulation of methane at the place of the break. Given the design, ${ }^{2}$ there is no way to detain the methane flow if the pump is not stopped. For this reason, several modifications were suggested to study their impact on the end state frequency. One suggestion was to place a cutoff valve before the evaporator, shown as VCM-A in Fig. 9. The other was to observe the failure probability of the pump necessary to achieve a risk reduction comparable to that achieved with the addition of the new valve.

The results show that the addition of the new cutoff valve reduces the end state frequency of EXPLOSIONM from $6.5 \times 10^{-8}$ to $1.4 \times 10^{-10}$ year $^{-1}$. In order to achieve this same reduction in frequency of the methane explosion end state, it would be necessary to decrease the failure probability of the

\footnotetext{
${ }^{2}$ We must iterate that this study is based on the design presented here, and may not reflect the true plant design.
}

pump from $2.78 \times 10^{-4}$ to $6 \times 10^{-7}$, which falls outside the $90 \%$ range of certainty considered in this study.

\section{Conclusions}

Despite the major limitations and uncertainties due to the lack of operational experience at the complex, the results reflect the importance of the methane line break event and the relative unimportance of the fact that the plants are coupled in this event. Furthermore, since the total frequency of the sequences that could affect health has a mean value of almost $7 \times 10^{-8}$ year $^{-1}$, and the methane explosion sequences contribute almost $90 \%$ to this total value, it becomes apparent that the possible design modifications should be concentrated on the hydrogen production plant. Since the methane explosion is the most dominant end state that could effect health, different modifications were suggested to reduce the frequency. As analyzed in this paper, the addition of a cutoff valve in the methane line can reduce the explosion frequency by two orders of magnitude. Results from 
other design changes, as well as procedural changes, such as placing a second operator to verify that the recirculator is shut down, are presented in the study's full report (Flores, 2005). It is necessary to perform a cost/benefit analysis to evaluate the design change, given the risk reduction calculated here. Finally a cost-benefit factor limit must be established for promoting design change for such already low accident frequencies. In addition, the use of end states that only affect economic risk can also be used for defining design changes.

Generic failure rates were employed, and when the data did not exist, conservative values were used. Despite the simplifications and not taking credit for recovery, the end state frequencies were small. Although the the analysis is simplified, if other factors were to be considered, such as taking credit for human actions, component repair, etc., further reduction in frequencies would be expected. More plant specific data and/or data with less uncertainty could help to refine the analysis.

Future work includes analyzing more initiating events, especially a detailed study of the chemical plant. Also, as mentioned in the events that take place in the reactor, the assumption that the chemical plant is unaffected will be removed in order to better evaluate the level of affectation of the events in one plant on the other. In particular, the most important interface between the plants is the isolation valves; the inclusion of these valves in the PSA will determine the importance of their failures and provide further insight into the coupling risks. In addition, more sensitivity studies should be conducted in order to determine the impact of possible modifications in the design and operation of the plant. If the sensitivity study results in important risk reduction, the next step is to evaluate the cost of the modification and present the cost/benefit or value/impact results as a piece of information important to consider in the decision making process.

Although the frequency of an accident in this complex is two orders of magnitude smaller than the frequency of core melt of a BWR, risk is never small enough, and engineers should always be prepared to look for design improvements in order to reduce risk.

\section{Acknowledgments}

The authors wish to thank the researchers at JAERI who are working on this project in Japan and providing the world with a possibility for less greenhouse gases and more power, in particular to Dr. Ohashi Hirofumi for his quick response to our questions.

\section{References}

AICHE, 1989. Guidelines for Process Equipment Reliability Data with Data Tables. American Institute of Chemical Engineers, New York.

Bari, R.A., et al., 1985. Probabilistic Safety Analysis Procedures Guide, NUREG/CR-2815 [BNL-NUREG-51559]. Brookhaven National Laboratory, New York.

Copinger, D.A., Moses, D.L., 2004. Fort Saint Vrain Gas Cooled Reactor Operational Experience Division of Systems Analysis and Regulatory Effectiveness. Office of Nuclear Regulatory Research U.S. Nuclear Regulatory Commission, Washington, USA.

Flores, A., Nelson, P.F., François, J.L., 2004. Análisis Preliminar de Riesgo de una Planta de Producción de Hidrógeno Utilizando el Proceso de Reformado de Metano con Vapor Acoplada a un Reactor Nuclear de Alta Temperatura. In: International Joint Conference Cancun 2004 LAS/ANS-SNM-SMSR, Cancun, Q.R., Mexico, 11-14 July 2004.

Flores, A., 2005. Análisis Probabilístico de Seguridad de una Planta de Reformado de Metano con Vapor Acoplada a un Reactor Nuclear de Alta Temperatura para la Producción de Hidrógeno. Master's Thesis. Engineering School, UNAM.

Inagaki, Y., Nishihara, T., et al., 2003. Research and development program on HTTR Hydrogen production system. In: Proceedings of the International Conference on Global Environment and Advanced Nuclear Power Plants, Kyoto, Japan, 15-19 September 2003.

JAERI, 2005. http://www2.tokai.jaeri.go.jp/httr/eng/report_eng.html.

Miller, A.I., Duffey, R.B., 2005. Sustainable and economic hydrogen cogeneration from nuclear energy in competitive markets. Energy 30, 26902702.

Miller, A.I., 2004. Hydrogen economics for automotive use. In: Nuclear Production of Hydrogen - Technologies and Perspectives for Global Deployment. International Nuclear Societies Council (chapter 6).

Russell, K.D., Hoffman C.L., 1998. Systems Analysis Programs for Handson Integrated Reliability Evaluations (SAPHIRE) Version 6.0. System Overview Manual. NUREG/CR-6532 INEL/EXT-97-00151. 